\title{
Cystic fibrosis and renal tubular acidosis
}

\author{
J S FALLON, J T BROCKLEBANK, * E J SIMMONDS, AND J M LITTLEWOOD
}

Regional Cystic Fibrosis Unit and *Department of Paediatrics, St James's University Hospital, Leeds

SUMMARY A case is reported of a child who was born to consanguineous parents and who had the clinical features of two autosomal recessive conditions-cystic fibrosis and distal renal tubular acidosis.

Cystic fibrosis affects 1 in 2000 infants and is the most common inherited disease among white races. The basic metabolic defect is unknown, although chromosome 7 has recently been identified as the site of the defective gene. Increased concentrations of sodium and chloride in the sweat are usually diagnostic of the condition and a defect of chloride reabsorption has been found. When renal function has been examined in cystic fibrosis defects in renal tubular handling of sodium have been found. ${ }^{1}$ These have not been associated with clinically recognised abnormalities of renal function.

In contrast, distal renal tubular acidosis is rare. Most cases are sporadic but it may occur in families. The primary defect in distal renal tubular acidosis is a defect in the acidification of urine caused by an inability to generate an adequate hydrogen ion gradient between the blood and tubule fluid. The nature of the cellular defect is unknown but may be a cellular metabolic defect. ${ }^{2}$ Similarly, the basic metabolic defect in patients with cystic fibrosis is unknown but the primary defect may be in ion transport. ${ }^{3}$

We describe here the association of distal renal tubular acidosis and cystic fibrosis in the same patient.

\section{Case report}

The patient was a baby girl, the third child of healthy Asian parents of Pakistani origin, who were first cousins. Pregnancy was normal and the birth weight was $3050 \mathrm{~g}$. Her immediate neonatal condition was satisfactory, although she had bilateral talipes equinovarus. There was no family history of either cystic fibrosis or renal tubular acidosis. She had a positive meconium screening test for cystic fibrosis (B M Meconium test) and a low faecal chymotrypsin concentration of less than $10 \mu \mathrm{g} / \mathrm{g}$ (normal range greater than $90 \mu \mathrm{g} / \mathrm{g}$ ). A sweat test was arranged at 3 weeks of age, and on the 10th day she was discharged home.

At 13 days of age she was thought to have gastroenteritis and admitted to an infectious disease unit. She was wasted, dehydrated, and acidotic with a pronounced disturbance of the serum concentrations of electrolytes: sodium $128 \mathrm{mmol} / \mathrm{l}$, potassium $2.0 \mathrm{mmol} / \mathrm{l}$, bicarbonate $7.4 \mathrm{mmol} / \mathrm{l}$, urea 13.6 $\mathrm{mmol} / \mathrm{l}$, and creatinine $65 \mu \mathrm{mol} / \mathrm{l}$. She was rehydrated with intravenous fluid and electrolyte replacement but failed to gain weight satisfactorily despite an adequate energy intake and dietary manipulations including a diet free of lactose and cows' milk.

She was transferred to our hospital at 31 days of age for further investigation. The diagnosis of cystic fibrosis was supported by raised concentrations of electrolytes in sweat: sodium $99 \mathrm{mmol} / \mathrm{l}$, and chloride $90 \mathrm{mmol} / \mathrm{l}$, sweat weight $-205 \mathrm{mg}$ ) and further low faecal chymotrypsin concentrations. A repeat sweat test also gave abnormal results.

Although adequate oral feeds and electrolytes were given, she failed to gain weight and was dry skinned and dehydrated with pronounced loss of skin elasticity. The urine was not infected but was persistently alkaline (pH 7.5) despite a severe systemic acidosis ( $\mathrm{pH} 7 \cdot 15)$, suggesting the diagnosis of distal renal tubular acidosis. Further investigations showed persistent plasma electrolyte abnormalities: sodium $138 \mathrm{mmol} / \mathrm{l}$, potassium $3 \cdot 1 \mathrm{mmol} / \mathrm{l}$, bicarbonate $10.3 \mathrm{mmol} / \mathrm{l}$, creatinine $45 \mu \mathrm{mol} / \mathrm{l}$, and a $\mathrm{pH}$ of 7.15. At this time urine electrolytes were: sodium $28 \mathrm{mmol} / \mathrm{l}$, potassium $33 \mathrm{mmol} / \mathrm{l}$, bicarbonate $12 \mathrm{mmol} / \mathrm{l}$, creatinine $1.6 \mathrm{mmol} / \mathrm{l}$, and a $\mathrm{pH}$ of 7.5. The fractional excretion of bicarbonate was 3.28. Other investigations done at this time were as follows: haemoglobin concentration $146 \mathrm{~g} / \mathrm{l}$; white cell count $11.6 \times 10^{9} / 1$; and platelets $244 \times 10^{9} / 1$ with normal leucocyte morphology. Radiographs of skull and abdomen, and an intravenous pyelogram, were normal. There was no radiological or biochemical evidence of rickets.

The infant was treated with high energy feeds, pancreatic enzyme supplements, prophylactic flucloxacillin, vitamin supplements, and regular chest physiotherapy. The distal renal tubular acidosis was treated with regular oral electrolyte supplements adjusted according to the plasma electrolyte concentrations. 
At the age of 7 years she is well and development is normal. Her height of $108.3 \mathrm{~cm}$ and weight of 16.4 $\mathrm{kg}(89 \%$ height for age, $70 \%$ weight for age, and $88 \%$ weight for height) both lie below the third centile. Her electrolyte concentrations are variable, but usually normal with daily oral supplements adjusted on regular electrolyte values. There is no evidence of rickets. The talipes equinovarus has responded to serial splinting and physiotherapy and she walks normally. Her chest radiograph is within normal limits with a Chrispin-Norman score of 3.

\section{Discussion}

Renal tubular acidosis is a syndrome characterised by systemic hyperchloraemic acidosis with inappropriately high urine $\mathrm{pH}$, excessive urinary sodium bicarbonate excretion, and normal glomerular function. In the distal tubular type the urinary $\mathrm{pH}$ remains high during severe acidosis (blood $\mathrm{pH}$ less than 7.2). In contrast patients with proximal renal tubular acidosis can acidify their urine in severe acidosis, and the complex dysfunction of the proximal tubule characteristic of Fanconi's syndrome is absent. Although there is bicarbonate wastage in distal renal tubular acidosis, it is usually less than $8 \%$ of the fraction of filtered bicarbonate, and the acidosis can be corrected with small amounts of sodium bicarbonate.

This child had an inappropriately alkaline urine in the presence of severe acidosis. There is no doubt that she also has cystic fibrosis. The association of these two inherited conditions in the same patient may be a chance finding illustrating the increased occurrence of complex metabolic problems in children of consanguineous marriages. Electrolyte disturbances from a number of causes are common in patients with cystic fibrosis and should be considered in such circumstances. Decreased electrolyte concentrations and profound alkalosis in patients with cystic fibrosis caused by chronic loss of sweat electrolytes and mild gastrointestinal disturbances have been reported. ${ }^{4}$ Decreased electrolyte concentrations caused by sweat losses in hot weather have been reported after the original observations by di Sant' Agnese et al. ${ }^{5}$ In addition to excessive losses both modern low solute milks and breast feeding may lead to an inadequate net electrolyte intake in the infant with cystic fibrosis. ${ }^{6}$

Our patient was unusual because her reduced electrolytes were accompanied by severe acidosis with serum and urinary electrolytes compatible with a profound renal tubular disorder. Finally, in children with an inherited disorder whose parents are first cousins (as are $60 \%$ of the Asian population in our area) an additional recessive condition should be suspected if the clinical picture of a disorder is atypical or the response to treatment unsatisfactory.

\footnotetext{
References

1 Robson AM, Tateiski S, Ingelfinger JR, Strominger DB, Klahr S. Renal function in patients with cystic fibrosis. $J$ Pediatr 1971;79:42-50.

2 Mearns RC, Sebastian A, McSherry E. Renal acidosis. Kidney Int 1972;1:322-40.

${ }^{3}$ Sarshcer EJ, Breslaw JL. Cystic fibrosis: a disorder of calcium stimulated secretion and transepithelial sodium transport. Lancet $1982 ; \mathbf{i}: 368-70$.

${ }^{4}$ Beckerman RC, Taussig LM. Hypoelectrolytemia and metabolic alkalosis in infants with cystic fibrosis. Pediatrics 1979;63:580-3.

5 di Sant' Agnese PA, Darling RC, Peresa GA. Sweat electrolyte disturbances associated with childhood pancreatic disease. Am J Med 1953;15:777-84.

${ }^{6}$ Laughlin JJ, Brady MS, Eigan H. Changing feeding trends as a cause of electrolyte depletion in infants with cystic fibrosis. Pediatrics 1981;68:203-7.
}

Correspondence to Dr EJ Simmonds, Regional Cystic Fibrosis Unit and Department of Paediatrics, St James's University Hospital, Leeds LS9 7TF.

Accepted 8 December 1988

\title{
Diffuse nephrocalcinosis and idiopathic renal hypercalciuria
}

\author{
V K AGGARWAL AND K VERRIER JONES
}

Department of Renal Medicine, Royal Infirmary, Cardiff

SUMMARY A 12 year old boy presented with primary nocturnal enuresis. Investigation showed extensive bilateral nephrocalcinosis of no obvious or recognised cause. Persistent severe renal hyper- calciuria was confirmed by an intravenous calcium infusion. Idiopathic hypercalciuria is not a common cause of nephrocalcinosis and has not previously been described in a child. 